\title{
RELATOS DE PESQUISAS \\ GESTÃO DO CONHECIMENTO E DESEMPENHO ORGANIZACIONAL: INTEGRAÇÃO DINÂMICA ENTRE COMPETÊNCIAS E RECURSOS
}

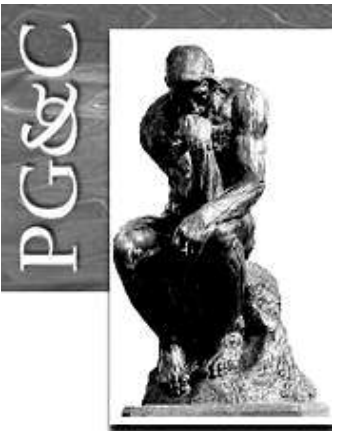

\author{
Jurema Suely de Araújo Nery Ribeiro \\ Doutoranda em Sistemas de Informação e Gestão do Conhecimento pela \\ Universidade FUMEC, Brasil. Professora da Faculdade Pitágoras, Brasil. \\ E-mail: jurema.nery@gmail.com \\ Marco Antônio Calijorne Soares \\ Mestrando em Sistemas de Informação e Gestão do Conhecimento pela \\ Universidade FUMEC, Brasil. \\ E-mail: marco.calijorne@techsysinfo.com \\ Paulo Henrique Jurza \\ Doutorando em Sistemas de Informação e Gestão do Conhecimento pela \\ Universidade FUMEC, Brasil. \\ E-mail: paulo.jurza@gmail.com \\ Fabricio Ziviani \\ Doutor em Ciência da Informação pela Universidade Federal de Minas \\ Gerais, Brasil. Professor da Universidade FUMEC, Brasil. \\ E-mail: fabricio.ziviani@fumec.br \\ Jorge Tadeu de Ramos Neves \\ Doutor em Génie Industriel Et Gestion de L'innovation Techno pelo École Centrale \\ de Paris, França. Professor da Universidade FUMEC, Brasil. \\ E-mail: jorgeneves@fumec.br
}

\section{Resumo}

Diversos desafios vêm sendo impostos à gestão das organizações contemporâneas na busca por diferenciais competitivos e conquista de posições estratégicas de mercado. A necessidade de estabelecer patamares mais elevados de desempenho estimula a reflexão acerca dos fatores que afetam o desempenho do indivíduo e da organização diante de um contexto marcado pela competitividade e por constantes mudanças na dinâmica mercadológica. O conhecimento torna-se um dos principais fatores competitivos das organizações e a gestão do conhecimento pode contribuir para que o conhecimento seja utilizado de forma a maximizar o desempenho e os resultados organizacionais. Este artigo pretende demonstrar a importância da gestão do conhecimento para alcance de desempenhos organizacionais superiores através da integração dinâmica entre competências e recursos, considerando influência e operacionalidade no contexto organizacional. Este artigo de caráter teórico e exploratório, realiza uma breve revisão da literatura especializada no campo da gestão do conhecimento e desempenho organizacional, apresentando os principais conceitos e abordagens, a fim de compreender a interação destas com os construtos competências e recursos. Para tal propõe-se um modelo sistematizado, de cunho teórico, para a gestão do conhecimento e desempenho organizacional de forma estruturada e integrada dos construtos competências e recursos. Os resultados obtidos sinalizam que a compreensão das relações dinâmicas entre competências e recursos ancorados pela gestão do conhecimento é o que vai assegurar a condução adequada dos mecanismos pelos quais o desempenho organizacional pode ser sustentado ao longo do tempo.

Palavras-chave: Competências e Recursos. Desempenho e Resultados Organizacionais. Gestão do Conhecimento.

Perspectivas em Gestão \& Conhecimento, João Pessoa, v. 7, Número Especial, p. 4-17, mar. 2017. http://periodicos.ufpb.br/ojs2/index.php/pgc. ISSN: 2236-417X. Publicação sob Licença (cc) EY-Nc-ND 


\title{
KNOWLEDGE MANAGEMENT AND ORGANIZATIONAL PERFORMANCE: DYNAMIC INTEGRATION BETWEEN COMPETENCES AND RESOURCES
}

\begin{abstract}
Several challenges have been imposed on management of contemporary organizations in the quest for competitive advantage and strategic market positions. The need to establish higher levels of performance stimulates reflection about the factors that affect the performance of the individual and the organization in a context marked by competitiveness and constant changes in market dynamics. The knowledge becomes one of the main competitive factors of organizations and knowledge management can contribute to that knowledge is used to maximize the organizational performance and results. This article aims to demonstrate the importance of knowledge management for range of superior organizational performance through dynamic integration between competences and resources, considering the influence and operation in the organizational context. This article theoretical and exploratory character and performs a brief review of the specialized literature in the field of knowledge management and organizational performance, introducing the main concepts and approaches in order to understand the interaction of these with the constructs competences and resources. To this end it is proposed a systematic, theoretical model for knowledge management and organizational performance in a structured and integrated competences and resources constructs. The results obtained indicate that the understanding of the dynamic relationships between competences and resources anchored by knowledge management is what will ensure the proper conduction of the mechanisms by which organizational performance can be sustained over time.
\end{abstract}

Keywords: Competences and Resources. Organizational Performance and Results. Knowledge Management.

\section{INTRODUÇÃO}

A constante corrida por uma posição privilegiada no mercado ou até mesmo pela sobrevivência têm levado as organizações a atuar de maneira diferente, com estratégias diversificadas e mais elaboradas, bem como identificar recursos e atividades que tragam vantagem competitiva, assim como Barney (1991) e Porter (1985) expõem como condição para a superioridade de desempenho. A compreensão do desempenho das empresas e suas estratégias corporativas têm sido alvo de constates estudos através da análise da estrutura competitiva do mercado como um elemento central, de acordo com Porter (1991). Porém, as organizações também estão expostas às influências inerentes ao seu ambiente interno. Deste modo, ter conhecimento e controle das questões endógenas e exógenas à organização é fator primordial para condução do desempenho organizacional.

A Era do Conhecimento cria uma nova mentalidade na sociedade, no intuito de desenvolver práticas em comunidades do conhecimento humano, direcionando as pessoas a trabalharem em equipe na busca de solução para os problemas. Neste contexto, o conhecimento torna-se um elemento fundamental das organizações e por isso, saber como administrá-lo, torna-se um grande desafio. A comunidade de prática pode ser uma comunidade que aprende, segundo Wenger (1999), pois são compostas por pessoas que têm compromisso de agregar as melhores práticas, não é tão somente um agregado de pessoas definidas por algumas características, são pessoas que aprendem, constroem e fazem a gestão do conhecimento. Para Senge (1998) o processo de aprendizagem na organização ocorre mediante condições concretas para que as pessoas aprendam a criar sua própria realidade, auxiliando-as a compreender o contexto em que vivem e a com ele interagir. Assim, a gestão do conhecimento contribui para que o conhecimento seja utilizado de forma a maximizar o desempenho e consequentemente os resultados alcançados pelas empresas.

Estudar o comportamento da organização e as razões do seu crescimento é determinante para compreender os fatores que levam as firmas a terem desempenhos superiores e por consequência umas superarem as outras. Diante da perspectiva da competição sustentável, as empresas devem promover a criação do conhecimento e as melhores práticas, através da criação de

Perspectivas em Gestão \& Conhecimento, João Pessoa, v. 7, Número Especial, p. 4-17, mar. 2017. 
competências distintivas, bem como na transferência dessas competências, para toda a organização, com o objetivo de aprimorar os negócios, gerando resultados promissores. Assim, inserida neste contexto, a questão que norteia essa pesquisa é a seguinte: Como a gestão do conhecimento pode integrar competências e recursos em uma organização, a fim de promover um desempenho superior?

O contexto que envolve esta questão de pesquisa é permeado por inúmeras variáveis, e para compreendê-las, faz-se necessário entender o que é o conhecimento e qual sua importância para as organizações; compreender como ocorre a gestão do conhecimento e verificar como conectar a gestão de competências à gestão de recursos organizacionais, a fim de se obter o melhor desempenho.

O desenvolvimento do trabalho está organizado em seis seções, incluída esta introdução. A segunda seção trata-se do referencial teórico onde são tratados conceitos e algumas questões relativas à gestão do conhecimento, desempenho organizacional e os construtos: recursos e competências. A terceira seção apresenta a metodologia do artigo. Os resultados são apresentados na quarta seção através do detalhamento da integração entre os construtos e o modelo proposto. $\mathrm{Na}$ quinta seção encontram-se as conclusões e na última seção as referências bibliográficas.

\section{REFERENCIAL TEÓRICO}

\subsection{Gestão do conhecimento}

O gerenciamento eficiente e eficaz do conhecimento - criação, armazenamento, compartilhamento, desenvolvimento e aplicação - tem sido um desafio constante para os gestores contemporâneos, em decorrência da dificuldade de se mensurá-lo objetivamente afirma Polanyi (1966). Entender sobre a gestão do conhecimento tem sido alvo de importantes estudos realizados nos últimos anos, porém ainda não existe um consenso conceitual entre os teóricos interessados pelo tema em questão. Existe na literatura um grande número de abordagens e tentativas de definição.

Fato interessante alertado por Senge $(1998$, p.167) é que "as organizações só aprendem por meio de indivíduos que aprendem. A aprendizagem individual não garante a aprendizagem organizacional. Entretanto sem ela, a aprendizagem organizacional não ocorre". Sveiby (2003), por exemplo, classifica as abordagens da gestão do conhecimento em duas categorias principais: as orientadas para a gestão da informação e as orientadas para a aprendizagem organizacional e competências.

Moresi (2001, p.137), apresenta o conceito de gestão do conhecimento como "o conjunto de atividades que busca desenvolver e controlar todo tipo de conhecimento de uma organização, visando à utilização na consecução de seus objetivos". Complementa ainda que os gestores devem estabelecer políticas, procedimentos e tecnologias orientadas para o efetivo gerenciamento da base de conhecimento existente nos departamentos da organização, favorecendo a ocorrência da gestão do conhecimento e o apoio ao processo decisório em todos os níveis organizacionais. Nesse sentido, é primordial que tais políticas, procedimentos e tecnologias criem as condições necessárias para os processos de coleta, distribuição e utilização efetiva e eficaz do conhecimento (MORESI, 2001).

Angeloni (2002, p. 15) comenta que "não se pode negar a relevância da gestão do conhecimento no meio organizacional como técnica de gestão, fato que exige uma nova postura em relação aos desafios organizacionais contemporâneos". Smith ee Lyles (2003, p. 12), definem a gestão do conhecimento como "uma perspectiva econômica do valor estratégico do conhecimento organizacional, que facilita a aquisição, compartilhamento e utilização do conhecimento". Já Lacombe (2005, p. 343), esclarece a gestão do conhecimento é "o conjunto de esforços ordenados e sistematizados visando a criar um conhecimento novo, difundi-lo na organização para os que dele precisam e incorporá-lo a produtos, serviços e sistemas, bem como a protegê-lo contra o uso

Perspectivas em Gestão \& Conhecimento, João Pessoa, v. 7, Número Especial, p. 4-17, mar. 2017. 
indevido", e pode ser aplicada em diversas organizações, adaptando-se os métodos, as práticas e sua finalidade.

Nonaka e Takeushi (1997), ao definirem a teoria de criação do conhecimento, identificaram quatro formas de difusão de conhecimento, que se expandem através da organização em um movimento em espiral, que retornam às fases nas quais já passaram num ato contínuo e expansor.

É importante ressaltar ainda, de acordo com Allee (2000) e Alavi e Leidner (2001), que a administração do conhecimento como recurso sempre existiu nas organizações, seja através dos processos de codificação, de armazenamento ou de disseminação, entretanto, atualmente a diferença encontra-se no reconhecimento dos ativos de conhecimento como recursos críticos e na crescente compreensão da necessidade de ações estratégicas para a sua promoção, conforme argumentam Spender (1996) e Davenport e Prusak (1998). A capacidade dinâmica de gerenciar esse recurso é definida por Teece, Pisano e Shuen (1997) como única para cada organização e pode ser considerada fonte de vantagem competitiva e desempenho superior.

Assim, a gestão do conhecimento tem sido considerada por autores como Davenport e Jarvenpaa e Beers (1996) como uma estratégia para a empresa lidar e gerir seu conhecimento, a fim de obter vantagens competitivas. Segundo Salim (2001), a gestão do conhecimento pode ser sintetizada como um processo intencional, destinado a sustentar o desempenho da organização. Interessante notar que Leite (2004) conclui que as empresas brasileiras ainda possuem poucas práticas que relacionam a gestão do conhecimento à gestão de competências, estratégia empresarial e resultado. Então, a Gestão de Conhecimento leva a empresa a se adiantar às suas concorrentes, ao possibilitar a criação um desempenho organizacional superior sobre seus pares.

\subsection{Desempenho Organizacional}

A visão empresarial baseada no conhecimento tem se tornado uma das ações mais relevantes da administração estratégica, ou seja, a produção do conhecimento passou a ser força propulsora da economia para as empresas. Ghemawat (1986), afirma que as organizações precisam empreender diferentes estratégias de lucratividade e crescimento tomando decisões estratégicas que envolvam a combinação adequada de recursos, estruturas e competências, que façam com que elas desenvolvam produtos e serviços para atender às necessidades de seus clientes e stakeholders, e assim, atingir um desempenho superior.

Grant (1991) afirma que a procura constante das empresas pela maximização do emprego dos recursos causa os desequilíbrios das firmas e dos mercados, sendo que dessas imperfeições do mercado é que as empresas extraem suas vantagens competitivas. Portanto, a noção de vantagem competitiva requer o desenvolvimento (renovação, investimento e alavancagem) de novos recursos e capacidades ou a combinação de habilidades (capacidades/competências) ou ainda, de recursos únicos (dinâmicos/essenciais) que construa, mantenha e realce as vantagens distintivas e difíceis de imitar; além da exploração das capacidades internas e externas e dos recursos (COLLIS; MONTGOMERY, 1995; TEECE; PISANO; SHUEN, 1997 e PRAHALAD; HAMEL, 2006).

Barney (1991) afirma que o caminho do sucesso, quando da implementação de uma estratégia, passa pela criação de condições específicas que permitam à organização identificar aqueles recursos considerados relevantes na obtenção da vantagem competitiva sustentável, sem que seus concorrentes sejam capazes de implementarem simultaneamente ou mesmo imitá-la. Segundo Drucker (1993) desenvolver as práticas sistemáticas para administrar a autotransformação é um dos desafios mais importantes impostos às organizações da sociedade do conhecimento. A organização tem que estar preparada para: abandonar o conhecimento que se tornou obsoleto, aprender a criar o novo através da melhoria contínua de todas as atividades, desenvolver novas aplicações, a partir de seus próprios sucessos, e realizar a inovação contínua como um processo organizado. A geração de um desempenho superior vai depender das receitas obtidas das estratégias

Perspectivas em Gestão \& Conhecimento, João Pessoa, v. 7, Número Especial, p. 4-17, mar. 2017. 
e dos custos da execução destas estratégias - custos de desenvolvimento, pesquisa, contratação, treinamento, etc.

O uso de múltiplas medidas para se definir um conceito tão complexo como o desempenho organizacional tem sido sugerido por diversos pesquisadores. Não existe consenso sobre qual é a definição ideal para desempenho organizacional de acordo com Barney (1996), apesar de terem sido propostas inúmeras definições, tendo em vista que cada medida de desempenho tem suas limitações, uma multiplicidade de abordagens seria adequada. Hirschey e Wichern (1984) sugerem que as medidas contábeis não refletiriam o mesmo fenômeno subjacente de lucratividade capturado por medidas de mercado. Assim como, Kaplan e Norton (1992) propuseram uma combinação de quatro visões complementares do desempenho - visão financeira, visão dos clientes, visão dos processos internos e visão de inovação e aprendizado - designadas por balanced scorecard ou indicadores balanceados - que, ao mesmo tempo em que relatariam a história passada, também trariam indicações sobre o desempenho futuro esperado, baseado em medidas tangíveis e intangíveis de desempenho, ou seja, usando tanto indicadores financeiros quanto não financeiros. Vale refletir que tradicionais medidas contábeis-financeiras, por exemplo, podem indicar o desempenho de uma empresa no passado recente, mas não servem como garantia de desempenho futuro, em especial se as circunstâncias do futuro não repetirem as condições do passado (Barney, 1996).

Já Venkatraman e Ramanujam (1986) compararam as vantagens e desvantagens de indicadores operacionais vs. financeiros, bem como, de fontes primárias vs. fontes secundárias. Fiegenbaum, Hart e Schendelk (1996) propuseram o uso de diversos pontos de referência, tanto internos (entradas e resultados estratégicos) quanto externos (concorrentes, clientes, outros stakeholders). Barney (1996) organiza sua análise em torno de quatro abordagens do desempenho: sobrevivência, medidas contábeis, perspectiva de múltiplos stakeholders e medidas de valor presente. Barbosa e Cintra (2012) esclarecem que as metas organizacionais devem ser claras, mensuráveis, predefinidas e consensuais entre membros da organização e, se possível, com opinião de especialistas. $O$ fato de não haver metas padronizadas para todas as organizações dificulta a comparação de organizações e a identificação dos diferentes aspectos de desempenho empresarial.

Percebe-se diante do que foi apresentado que, desempenho organizacional é um fenômeno multifacetado e complexo, difícil de ser analisado sob uma concepção simplista, ou seja, conseguir organizar, em um todo integrado e consistente, as diferentes perspectivas do desempenho constitui um considerável desafio. Faz-se necessária a associação de diversas métricas para que uma empresa possa ser avaliada, ou seja, diversas perspectivas deverão ser consideradas para se avaliar se o sucesso foi ou não alcançado. Venkatraman e Grant (1986, p.71) corroboram quando explicam que "uma forte relação entre conceitos e suas medidas impulsionam o desenvolvimento da teoria". Verifica-se então que nenhuma medida individual conseguirá mensurar toda a riqueza e a complexidade do fenômeno de desempenho. $O$ desempenho deveria também ser comparado contra benchmarks e avaliado sob a luz do atingimento de objetivos pré-definidos. Medidas correntes e expectativas futuras de desempenho também deveriam ser comparadas com resultados passados no sentido de se avaliar sua melhora ou piora segundo Carneiro (2005).

\subsection{Os diferentes construtos}

\subsubsection{Recursos}

As decisões estratégicas da firma não são determinadas pelos mercados de fatores e de produtos, mas sim pela organização de planos e dos recursos (PENROSE, 1959). A partir dos anos 1990 cresce a lacuna que não conseguia ser preenchida pelos modelos de planejamento estratégico desenvolvidos até então. As teorias tradicionais de estratégia não explicavam a dinâmica dos ambientes concorrenciais e a necessidade de se criar e gerir capacidades. Existe a necessidade em

Perspectivas em Gestão \& Conhecimento, João Pessoa, v. 7, Número Especial, p. 4-17, mar. 2017. 
explicar os pontos fortes (recursos, habilidades, aprendizado coletivo etc.) da firma individual, compreender como estes afetam o desempenho dos competidores e entender também como a ideia de competência essencial pode ser colocada na prática e assim por diante (BARNEY, 1996; COLLIS; MONTGOMERY, 1995; FOSS, 1997; TEECE; PISANO; SHUEN, 1997). Nesta nova perspectiva a origem da vantagem competitiva é deslocada de fora para dentro das organizações (combinação das perspectivas externa e interna) e sugere que a adoção de novas estratégias esteja restrita ao nível corrente de recursos da firma. Segundo Foss (1997), a análise baseada em recursos da vantagem competitiva emerge, portanto, da insatisfação e/ou insuficiência das contribuições das análises de estratégia e vantagem competitiva.

Pode-se dizer que no campo da estratégia o conhecimento ganhou especial destaque como recurso estratégico, a partir dos estudos realizados por autores, como Wernerfelt (1984), Rumelt (1984), Barney (1986; 1991), Grant (1991) e Peteraf (1993). Estes autores explicam que o desempenho superior das empresas advém das capacidades diferenciadas e do conjunto de recursos (tangíveis e intangíveis), que permitem às empresas conquistarem e sustentarem vantagens competitivas por longos períodos de tempo, em seus mercados consumidores.

O recurso conhecimento é considerado por Porter (1991), como a única vantagem a oferecer diferenciação para uma competição sustentável, ou seja, as empresas devem promover a criação do conhecimento e as melhores práticas, na transferência das competências, para toda a organização, com o objetivo de aprimorar os negócios. Em decorrência disso, surge a noção de sustentabilidade como função das barreiras à imitação dos recursos, onde a condição básica de heterogeneidade da vantagem seja preservada e seja durável ao adicionar valor. Assim, a sustentabilidade é subsequente a uma posição superior ganha pela firma, gerando retornos maiores ao resistirem à diluição pelo comportamento dos competidores.

Kretzer e Menezes (2006) corroboram sugerindo que as condições pelas quais os recursos geram vantagem competitiva podem ser agrupadas em duas dimensões: I. Vantagem competitiva posicional - reúne as condições que definem a natureza, o tipo, a magnitude e a natureza do estoque de recursos adquiridos ou construídos pela firma, enfocando os fatores que dificultam ou limitam a livre expansão ou a imitação por outras firmas; II. Vantagem competitiva sustentável - reúne as condições que garantem e sustentam a firma a reter os recursos que são específicos a ela ou não são facilmente transferíveis.

Portanto, "a competitividade deriva da criação de capacidades diferenciadas necessárias para sustentar o crescimento em um ambiente de seleção competitiva" (Cantwell, 2005, p. 561). Uma organização possui vantagem competitiva se for capaz de criar mais valor econômico do que sua concorrente no mercado. $O$ valor econômico criado por uma empresa na prestação de um bem ou serviço é o resultado da diferença entre as vantagens obtidas pelos compradores do bem e o custo econômico para a empresa, afirmam Barney e Clark (2007).

\subsubsection{Competências}

Até certo ponto da história moderna, e até mesmo nos dias atuais em algumas economias, a procura da melhoria no desempenho organizacional era focado no processo produtivo, em máquinas, porém, a gestão do conhecimento tem tomado cada vez mais espaço nos processos de melhoria do desempenho sustentável e um subsistema crucial neste processo é o de gestão de competências.

Brandão e Guimarães (2001) reúnem algumas importes definições de competência sob a ótica de diferentes autores. Sparrow e Bognanno (1993) tratam competência como um conjunto de atitudes que combinadas permitem ao indivíduo adaptar-se com velocidade a um ambiente mutável a ainda conseguir inovar e continuar aprendendo. Zarifian (1996, p. 5) definiu competência como "assumir responsabilidades frequente a situações de trabalho complexas [aliado] (...) ao exercício sistemático de uma reflexividade no trabalho". Já Ropé e Tanguy (1997) acreditam que um aspecto

Perspectivas em Gestão \& Conhecimento, João Pessoa, v. 7, Número Especial, p. 4-17, mar. 2017. 
essencial da competência é que esta não pode ser compreendida de forma separada da ação. Dutra, Hipólito e Silva (1998) conceituam competência como a capacidade de uma pessoa de gerar resultados dentro dos objetivos organizacionais. Já Durand (1998) define um conceito de competência baseado em três dimensões, sendo conhecimento, habilidade e atitude, englobando não só questões técnicas, mas também a cognição e as atitudes relacionais ao trabalho.

Avaliando as definições dos diferentes autores apresentadas, verifica-se que apesar de prismas distintos, e de não haver uma unicidade entre os conceitos, todas se integram através de atributos análogos, ou seja, indivíduos (ou o grupo de trabalho) com certas características e habilidades utilizam de seus conhecimentos para gerar vantagem competitiva para suas organizações através de atitude proativa.

Para Levy-Leboyer e Prieto (1997), existem três formas de desenvolver competências: pela formação prévia, antes da vida ativa; durante a vida ativa e mediante a vida ativa, ou seja, pelo exercício profissional. Já Ruas, Antonello e Boff. (2005) definem que as competências podem ser subdivididas em duas dimensões: estratégica, onde as competências organizacionais encontram-se estreitamente correlacionadas com a visão, missão e intenção estratégica; e intermediária onde as competências são observadas nos macroprocessos executados e vinculadas a áreas e funções. Destarte, o uso dessas dimensões auxilia no desdobramento progressivo das competências estratégicas para as competências funcionais.

Portanto a competência organizacional consiste na mobilização dos recursos e sua aplicação aparecerá como resultado no desempenho.

Entender o conceito de competência é importante para que dessa forma, a compreensão da definição de gestão da competência aconteça de maneira mais natural. Ocieczek, Sapeta e Prym (2009) definem gestão de competências como ações tomadas pelas organizações, com o objetivo de garantir conhecimento, experiências e habilidades a fim de permitir a concretização da visão da empresa, realização das estratégias e metas organizacionais. Pode-se então identificar que a competência é atribuída ao indivíduo e a gestão da competência deve ser promovida pela organização.

Ao iniciar-se um processo de gestão de competências, a organização precisa ter alguns objetivos importantes em seu foco, como: definição das normas de trabalho adequadas aos cargos, aderência na seleção de empregados e gestores para os cargos, preparação dos trabalhadores da organização para tarefas do presente e tarefas futuras, aumento do valor da companhia através do crescimento dos recursos humanos, utilização ao máximo dos pontos fortes dos colaboradores, minimizando seus pontos fracos, além do aumento do nível de satisfação dos funcionários e suas posições no mercado de trabalho. A implantação da gestão de competências em uma organização deve conduzir as empresas a alcançar suas metas. Desta forma, a gestão de competências tem como papel primário garantir que desempenho melhore no que diz respeito aos empregados e empregadores e suas atuações.

\section{METODOLOGIA}

Para elaboração deste artigo realizou-se uma pesquisa exploratória através de um levantamento bibliográfico teórico a respeito do tema, revisando, analisando, e discutindo conceitos existentes em literatura especializada e pesquisas já publicadas no campo da gestão do conhecimento, apresentando os principais conceitos, teorias e abordagens e, também, sobre a relação com o desempenho organizacional, a fim de contribuir nas construções teóricas sobre a relação destes na integração entre competências e recursos.

Adicionalmente foi proposto um modelo sistematizado para a gestão do conhecimento e desempenho organizacional, de cunho teórico, que pode vir a auxiliar a condução da gestão do conhecimento de forma integrada: identificando as competências (individual e organizacional) que a

Perspectivas em Gestão \& Conhecimento, João Pessoa, v. 7, Número Especial, p. 4-17, mar. 2017. 
empresa precisa ter e desenvolver e aprimorar ou adquirir os recursos necessários ao atingimento das metas organizacionais e sustentabilidade do negócio.

Será discutida, a seguir, a integração dos construtos recursos e competências com a gestão do conhecimento, bem como, reflexões relacionadas às suas relações e impactos mútuos no desempenho organizacional.

\section{RESULTADOS}

A gestão empresarial quando ocorre baseada no conhecimento pode ser considerada uma das mais significantes ações da administração estratégica, no momento em que a produção do conhecimento passou o elemento propulsor da economia para as empresas. Pressupõe-se, no que tange à competitividade empresarial, que as empresas possuem diferentes tipos de conhecimento, e que cada um pode proporcionar a base para uma vantagem competitiva. Assim, fica a critério da empresa atuar como agente organizador do conhecimento que existe dentro dela, tornando-o aplicável e gerador de novos conhecimentos, desempenhando essa tarefa de forma superior à concorrência, explicam Nonaka e Takeuchi (1997).

Neste contexto, as organizações precisam saber como gerir o conhecimento adquirido integrando de forma dinâmica recursos e competências, a fim de obterem um desempenho organizacional superior satisfatório e duradouro, conforme pode ser verificado na FIGURA 1.

Figura 1: Modelo sistematizado de gestão do conhecimento e desempenho

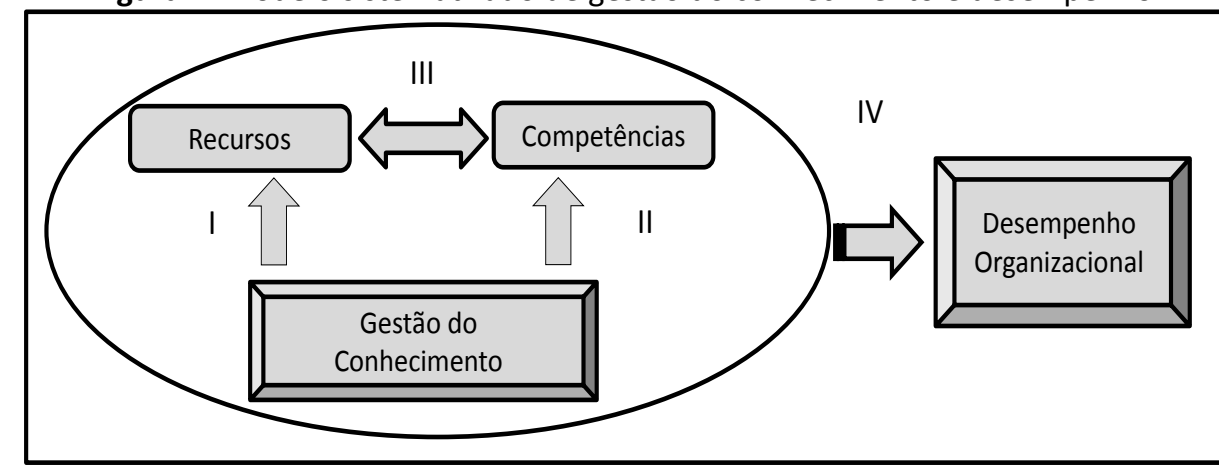

Fonte: Elaborado pelos autores (2016)

De acordo com as considerações realizadas, pode-se perceber o quão é oportuna a apresentação da relação da gestão do conhecimento com os construtos competências e recursos, a relação de integração dinâmica entre os construtos, bem como com a resultante do modelo, o desempenho organizacional, conforme desdobramentos a seguir.

\subsection{Gestão do conhecimento e recursos}

Tratar o conhecimento como um recurso organizacional básico traz oportunidades para as organizações. Cada vez mais, estudiosos, líderes e consultores de empresas consideram-no como elemento chave da vantagem competitiva e principal ativo das organizações. A base para manter o desempenho da empresa está firmada em seus recursos internos, representados pelas diferentes formas de promoção do conhecimento. Oliveira Júnior e Cavalcanti (2001) argumenta que a função central da empresa é usar meios eficientes para criar e transferir conhecimento. Assim, a empresa pode ser entendida como um estoque de conhecimento que é identificado e disponibilizado, para aplicação dentro de sua estrutura, na criação de novos conhecimentos.

Os recursos organizacionais podem ser vistos como fontes reais de competitividade, porém precisam ser desenvolvidos e controlados a fim de propiciarem resultados satisfatórios às organizações. Cabe à gestão do conhecimento criar condições favoráveis para que os recursos

Perspectivas em Gestão \& Conhecimento, João Pessoa, v. 7, Número Especial, p. 4-17, mar. 2017. 
relevantes sejam identificados e estruturados de forma a se tornarem raros, inimitáveis e insubstituíveis nos processos institucionais, conforme representação pelo algarismo I na Figura 1. Faz-se importante neste contexto que os recursos sejam identificados e estruturados sem que seus concorrentes sejam capazes de implementarem simultaneamente ou mesmo imitá-los, propiciando assim um desempenho superior sustentável. Portanto as empresas devem promover a criação do conhecimento e adoção de melhores práticas, na estruturação dos recursos, para toda a organização com o objetivo de aprimorar os negócios.

\subsection{Gestão do conhecimento e competências}

Com as mudanças que vêm acontecendo nas organizações e na forma como elas estão se adaptando aos desafios competitivos, a gestão de competências tem sido muito estudada e discutida. A implantação da gestão das competências, em meio a um projeto de gestão do conhecimento, traz resultados significativos para as organizações, melhorando diretamente o desempenho e os resultados destas empresas.

Diante da perspectiva da competição sustentável, as empresas devem promover a criação do conhecimento e as melhores práticas, através da obtenção de competências distintivas, e também na transferência dessas competências, para toda a organização, com o objetivo de aprimorar os negócios, gerando assim resultados promissores. Observa-se que a competição entre empresas, neste novo contexto do mercado, depende do seu conhecimento e de sua competência. Por este motivo, a criação do conhecimento deve ser construída na organização, dentro de envoltório de renovação de ideias e compartilhamento mútuo, entre os colaboradores e a própria organização.

Kochanski (1997) afirma que a gestão do conhecimento envolve a identificação das competências que distinguem o alto desempenho do médio desempenho. A capacidade dinâmica de gerenciar recurso conhecimento é definida por Teece, Pisano e Shuen (1997) como única para cada organização e pode ser considerada fonte de vantagem competitiva e desempenho superior.

Santos (2001) esclarece que a competência não é um estado ou um conhecimento que se tem e nem é resultado de treinamento, mas sim colocar em prática o que se sabe em um determinado contexto. Há competência apenas quando há competência em ação. Do ponto de vista empresarial, o que interessa é a prática: é o conhecimento aplicado que gera capacidade de produzir resultados, ou seja, competência.

Guzman e Wilson (2005) corroboram com o modelo proposto na FIGURA 1 quando definem a gestão de competências como processo de transferência de conhecimento organizacional, representada pelo algarismo I, e concluem que há necessidade de maior articulação de ferramentas de gestão, como a gestão do conhecimento e gestão de competências para a melhoria dos resultados em uma organização dinâmica.

Desta forma, o mercado competitivo atual exige que as empresas realizem a gestão de suas competências, conforme o que foi apresentado por Ocieczek, Sapeta e Prym (2009), onde as organizações devem tomar ações objetivando garantir o conhecimento, experiências e habilidades, permitindo a concretização da visão da empresa, realização das estratégias e atingimento das metas organizacionais a fim de gerar valor. Fazer isto de forma diferente dos demais players e de forma continuada garantirá a sustentabilidade de suas decisões.

A gestão do conhecimento, por sua vez, cumpre a finalidade de criar um ambiente de aprendizagem contínuo para que a gestão das competências seja uma realidade. Isso não significa que para gerir competência é preciso gerir conhecimento, mas a gestão do conhecimento cria o ambiente psicológico propício para tal. 


\subsection{Integração entre competência e recursos}

A relação simultânea entre competência e recursos está representada na FIGURA 1 pelo algarismo III. A articulação dinâmica ocorre, por exemplo, quando as organizações em prol dos direcionamentos estratégicos de desenvolvimento de competências organizacionais e individuais agregam valor como recursos raros, inimitáveis e insubstituíveis nos processos institucionais, inseridos em um contexto competitivo em os diferenciais concentram-se no capital humano, na cultura organizacional, nas relações entre os indivíduos, ou seja, nas competências organizacionais e humanas. Vale ressaltar que estas competências podem ser ou se tornar o diferencial competitivo quando vistas como oportunidade potencial ao gerar conhecimentos diferenciados para a organização.

\subsection{A vantagem competitiva sustentável como resultante}

O resultado da integração equilibrada entre os construtos competências e recursos ancorados pela gestão do conhecimento, estabelece o nível de impacto no desempenho da organização. Tal relação é identificada na FIGURA 1 pelo algarismo IV.

A gestão do conhecimento é a base para geração das competências e identificação dos recursos, uma vez que, o processo de geração de conhecimento depende de competências técnicas individuais e organizacionais e de recursos organizacionais, como: a força de trabalho da empresa, o conhecimento tácito da empresa, as informações do mercado e os clientes, infraestrutura organizacional, o que remete a relação conjunta estruturada destas três variáveis, proporcionando a organização alcançar a performance superior.

Porém, cabe ponderar que a convergência das articulações entre os construtos competência e recursos em resultados pode ser tornar um pouco complexa, em razão das constantes mudanças endógenas e exógenas, ocasionando a necessidade de acompanhamento constante, ajustes dos desvios através de ações corretivas assertivas, sejam elas pontuais ou estratégicas. Promover alinhamentos entre os construtos e descobrir oportunidades poderá ocorrer através da medição dos resultados de desempenho e comparação entre os esperados e os atuais. A criação de estratégias adequadas e a mobilização organizacional para a implementação da gestão de conhecimento promoverão certamente resultados superiores, através da gestão do fluxo do conhecimento dentro da organização, ou seja, criação, compartilhamento, disseminação, aplicação e controle, tornando efetivos os processos de gestão organizacional e tomada de decisão precisas e responsáveis.

As organizações, ao gerenciarem a incorporação de novos conhecimentos e experiências pessoais e ao estimularem a propagação do aprendizado como um dos seus principais ativos, estão contribuindo positivamente para o seu desempenho superior. A Gestão do Conhecimento está, portanto, intrinsecamente ligada à capacidade das empresas em utilizarem e combinarem as várias fontes e tipos de conhecimento organizacional para desenvolverem competências específicas, tanto individuais quanto organizacionais e recursos competitivos que se traduzem, permanentemente, em processos controlados e eficientes, sistemas gerenciais eficazes, liderança de mercado e por fim desempenhos superiores dos negócios organizacionais. Destarte, a gestão do conhecimento pode levar a organização a se adiantar às suas concorrentes, ao criar um desempenho superior sobre seus pares, detectando pontos que levem ao melhoramento contínuo, no intuito de se posicionar a frente de seus concorrentes e obter vantagem competitiva.

\section{CONCLUSÕES}

As contínuas mudanças no cenário competitivo motivam a busca de novas estratégias por parte das empresas, a fim de garantirem a sua permanência no mercado em um patamar

Perspectivas em Gestão \& Conhecimento, João Pessoa, v. 7, Número Especial, p. 4-17, mar. 2017. 
diferenciado. Este artigo demonstrou a importância da gestão do conhecimento para alcance de desempenhos organizacionais superiores através da integração dinâmica entre competências e recursos, considerando influência e operacionalidade no contexto organizacional. Para tanto, este artigo de caráter teórico, realizou uma breve revisão da literatura especializada no campo da gestão do conhecimento, apresentando os principais conceitos, teorias e abordagens e, também, sobre a relação com o desempenho organizacional $A$ fim de contribuir nas construções teóricas sobre a relação destes na integração entre os construtos competências e recursos, foi proposto um modelo sistematizado de gestão do conhecimento e desempenho.

Através da revisão teórica realizada e do modelo proposto, pode ser percebido que a criação de estratégias adequadas e a mobilização organizacional para a ocorrência da gestão de conhecimento é o que vai diferenciar cada vez mais a competitividade entre as empresas. 0 desempenho organizacional depende do conhecimento que estas criam e mobilizam no ambiente empresarial. A identificação e uso de ferramentas e metodologias apropriadas são fundamentais para se gerenciar o fluxo do conhecimento dentro da organização e direcioná-lo, proporcionando um ambiente favorável a sua criação, compartilhamento, disseminação, aplicação e controle, tornando efetivos os processos de gestão organizacional e tomada de decisão precisas e responsáveis. Porém, para que isso seja possível, torna-se imprescindível que as organizações propiciem a passagem do conhecimento tácito para o explícito, valorizando as experiências individuais, tornandoas coletivas em um processo de aprendizagem e incorporação de inovações contínuas em todos os níveis.

Verificou-se também que a chave para a formulação de estratégias diferenciadas está em compreender as relações integrativas entre recursos e competências, desempenho e gestão do conhecimento. Entender as condições endógenas e exógenas torna-se primordial para detectar as oportunidades de atuação. O cenário externo de atuação das organizações na atualidade é extremamente competitivo, globalizado e em constante mudança, já no ambiente interno as empresas possuem capacidades e habilidades diversas, bem como ativos tangíveis e intangíveis específicos que as diferenciam umas das outras, seja pela cultura organizacional diferente ou pelas experiências vividas. Surge a partir daí a necessidade de uma metodologia sistematizada e específica à realidade de cada organização, capaz de gerir a gestão do conhecimento de forma estruturada: identificando as competências individuais e organizacionais necessárias que a empresa precisa a ter e desenvolver e desenvolvendo, aprimorando ou adquirindo os recursos necessários ao atingimento das metas organizacionais e respectiva sustentabilidade do negócio, conforme apresenta o modelo sistematizado de gestão do conhecimento e desempenho apresentado na FIGURA 1.

Por tudo isso, a gestão do conhecimento precisa servista como uma abordagem sistematicamente estruturada para: facilitar o conhecimento utilizável nos processos de trabalho, aumentar o valor do que é oferecido no mercado; qualificar os profissionais do conhecimento; disseminar a inovação e assegurar o desenvolvimento dos indivíduos e das organizações. Ao invés da existência de feudos isolados de conhecimento, a gestão permite a construção de relacionamentos integrados e duradouros, onde os conhecimentos gerados são disseminados, compartilhados e aplicados e geridos pela empresa, sendo incorporados nos processos, nas tecnologias e nos produtos. Vale compreender também que a gestão dos recursos organizacionais e a gestão de competências são processos suportados pela gestão do conhecimento e que sua efetividade deve ser mensurada no desempenho organizacional para verificar os impactos sobre os resultados organizacionais obtidos. Aconselha-se em trabalhos futuros identificar a aplicabilidade do modelo proposto neste estudo, uma vez que este artigo se limitou à revisão bibliográfica e proposição do modelo. 


\section{REFERÊNCIAS}

ALAVI, Maryam; LEIDNER, Dorothy E. Review: Knowledge management and knowledge management systems: Conceptual foundations and research issues. MIS quarterly, p. 107-36, 2001.

ALLEE, Verna. The value evolution: addressing larger implications of an intellectual capital and intangibles perspective. Journal of Intellectual Capital, v. 1, n. 1, p. 17-32, 2000.

ANGELONI, Maria Terezinha. Organizações do conhecimento: infraestrutura, pessoas, e tecnologias. São Paulo: Saraiva, 2002.

BARBOSA, Allan Claudius Queiroz; CINTRA, Leandro Pinheiro. Inovação, competências e desempenho organizacional--articulando construtos e sua operacionalidade. Future Studies Research Journal: Trends and Strategy, v. 4, n. 1, p. 31-72, 2012.

BARNEY, Jay. B. Strategic Factor Markets: Expectations, Luck, and Business Strategy. Management Science, v. 32, n. 10, p. 1231-1241, 1986.

BARNEY, Jay. B. Firm resources and sustained competitive advantage, Journal of Management, v. 17, n. 1, p. 99-120, 1991.

BARNEY, Jay. B. Gaining and Sustaining Competitive Advantage. Reading, MA: Addison-Wesley Publishing Company, 1996.

BARNEY, Jay B.; CLARK, Delwyn N. Resource-Based Theory: Creating and Sustaining Competitive Advantage. New York: Oxford University, 2007.

BRANDÃO, Hugo Pena; GUIMARÃES, Tomás de Aquino. Gestão de Competências e Gestão de Desempenho: tecnologias distintas ou instrumentos de um mesmo construto? Revista de Administração de Empresas, v. 41, n. 1, p. 8-15, 2001.

CANTWELL, John. Innovation and competitiveness. The Oxford handbook of innovation, p. 543-567, 2005.

CARNEIRO, Jorge. Mensuração do desempenho organizacional: questões conceituais e metodológicas. Estudos em Negócios IV, p. 145-175, 2005.

COLLIS, David J.; MONTGOMERY, Cynthia A. Competing on Resources. Harvard Business Review, 1995.

DAVENPORT, Thomas H.; JARVENPAA, Sirkka L.; BEERS, Michael C. Improving knowledge work processes. Sloan Management Review, Cambridge Massachusetts, v. 37, n. 4, p. 53-65, Summer 1996.

DAVENPORT, Thomas H.; PRUSAK, Laurence. Conhecimento empresarial: como as empresas gerenciam seu capital intelectual. Rio de Janeiro: Campus, 1998.

DRUCKER, Peter. Sociedade pós-capitalista. São Paulo: Pioneira, 1993.

DURAND, Thomas. Forms of incompetence. In: Proceedings Fourth International Conference on Competence-Based Management. Oslo: Norwegian School of Management. 1998.

DURAND, Thomas. Forms of incompetence. In: Proceedings Fourth International Conference on Competence-Based Management. Oslo: Norwegian School of Management. 1998.

DUTRA, Joel Souza, HIPÓLITO José Antônio Monteiro, SILVA Cassiano Machado Gestão de pessoas por competências: o caso de uma empresa do setor de telecomunicações. In: ENCONTRO DA ASSOCIAÇÃO NACIONAL DOS PROGRAMAS DE PÓS-GRADUAÇÃO EM ADMINISTRAÇÃO, 22. Anais... Foz Iguaçu: ANPAD, 1998.

Perspectivas em Gestão \& Conhecimento, João Pessoa, v. 7, Número Especial, p. 4-17, mar. 2017. 
FIEGENBAUM, Avi; HART, Stuart; SCHENDELK, Dan. Strategic Reference Points Theory, Strategic Management Journal, v. 17, p. 219-235, 1996.

FOSS, Nicolai J. The resource-based perspective: an assessment and diagnosis of problems. DRUID Working Paper, Copenhagen: Copenhagen Business School, n. 97, v. 1, p. 1-39, 1997.

GHEMAWAT, Pankaj. Sustainable advantage. Harvard business review, n. 64, v. 5, p. 53-58, 1986.

GRANT, Robert M. The resource-based theory of competitive advantage: implications for strategy formulation. Califórnia Management Review, n. 33, v. 3, p. 114-135, 1991.

GUZMAN, Gustavo AC, and John WILSON. Transferindo conhecimento organizacional em redes produtivas modulares: a experiência brasileira. Redes entre organizações. São Paulo: Atlas, p. 170191, 2005.

HIRSCHEY, Mark; WICHERN, Dean W. Accounting and Market-Value Measures of Profitability: Consistency, Determinants and Uses, Journal of Business and Economic Statistics, v. 2, n. 4, p. 375383, 1984.

KAPLAN, Robert S.; NORTON, David P. 0 balanced scorecard: medidas que impulsionam o desempenho. Boston: Harvard Business Review, 1992.

KOCHANSKI, Jim. Competency-based management. Training e Development, v. 51, n. 10, p. 40-45, 1997.

KRETZER, Jucélio; MENEZES, Emílio Araújo. A Importância da Visão Baseada em Recursos na Explicação da Vantagem Competitiva. Revista de Economia Mackenzie, v. 4, n. 4, p. 63-87, 2006.

LACOMBE, Francisco José Masset. Recursos humanos: princípios e tendências. São Paulo: Saraiva, 2005.

LEITE, Eliane Santos. Gestão do conhecimento nas empresas brasileiras: relações entre estratégia empresarial, gestão de competências e de resultado e impactos no desempenho de negócios. 2004. 186 f. 2004. PhD Tese. Dissertação (Mestrado em Administração de Empresas), Programa de Pósgraduação, Pontifícia Universidade Católica do Rio de Janeiro, Rio de Janeiro, 2004.

LEVY-LEBOYER, Claude; PRIETO, José M. Prieto. Gestión de las competencias. Barcelona: Gestión 2000, p. 161, 1997.

MORESI, Eduardo Amadeu Dutra. Gestão da informação e do conhecimento. Inteligência organizacional e competitiva. Brasília: Editora Universidade de Brasília, p. 111-142, 2001.

NONAKA, Ikujiro; TAKEUCHI, Hirotaka. Criação de conhecimento na empresa: como as empresas japonesas geram a dinâmica da inovação. Rio de Janeiro: Campus, 1997.

OCIECZEK, Wioletta; SAPETA, Joanna; PRYM, Centrum Szkoleniowo-Edukacyjne. Competence Based Management. Zeszyty Naukowe Wyższej Szkoły Humanitas. Zarządzanie, n. 1, p. 56-63, 2009.

OLIVEIRA JÚNIOR, Moacir de Miranda; CAVALCANTI, M. Competitividade baseada no conhecimento. Gestão estratégica de negócios: evolução, cenários, diagnóstico e ação. São Paulo: Pioneira Thomson Learning, 2001.

PENROSE, Edith T. The theory of the growth of the firm. New York: Sharpe, 1959.

PETERAF, Margaret A. The cornerstones of competitive advantage: A resource-based view. Strategic Management Journal, v.14, n. 3, p. 179-191, 1993.

POLANYI, Michael. The tacit dimension. New York: Implizites Wissen, Frankfurt a. M.: Suhrkarnp, 1966.

Perspectivas em Gestão \& Conhecimento, João Pessoa, v. 7, Número Especial, p. 4-17, mar. 2017. 
PORTER, Michael E. Competitive advantage: creating and sustaining superior performance. London: Collier Macmillan, 1985.

PORTER, Michael E. Estratégia competitiva: técnicas para análise de indústrias e da concorrência. São Paulo: Campus, 1991.

PRAHALAD, Coimbatore K.; HAMEL, Gary. The core competence of the corporation. Springer Berlin Heidelberg, 2006.

ROPÉ, Françoise; TANGUY, Lucie. Saberes e competências. O uso de tais noções na escola e na empresa. Campinas, Papirus. 1997.

RUAS, Roberto; ANTONELLO, Claudia Simone; BOFF, Luiz Henrique. Os novos horizontes de gestão: aprendizagem organizacional e competências. Porto Alegre: Bookman, 2005.

RUMELT, Richard P. Towards a strategic theory of the firm. In: LAMB, R. B. (Ed.). Competitive Strategic Management. Englewood Cliffs: Prentice-Hall, 1984.

SALIM, Jean Jacques. Palestra gestão do conhecimento e transformação organizacional. Semana da EQ/UFRJp, p. 68, 2001.

SANTOS, Antônio Raimundo dos. Gestão do conhecimento: uma experiência para o sucesso empresarial. Champagnat, 2001.

SENGE, Peter. A quinta disciplina: arte e prática da organização que aprende. 2 ed. São Paulo: Best Seller, 1998.

SMITH, Mark E.; LYLES, Marjorie A. The Blackwell handbook of organizational learning and knowledge management. UK: Blackwell, 2003.

SPARROW, Paul R.; BOGNANNO, Mario. Competency requirement forecasting: issues for international selection and assessment. International Journal of Selection and Assessment, v. 1, n. 1, 1993.

SPENDER, John-Christopher. Making knowledge the basis of a dynamic theory of the firm. Strategic Management Journal, n. 17, p. 45-62, 1996.

SVEIBY, Karl Erick. A nova riqueza das organizações: gerenciando e avaliando patrimônios de conhecimento. Campus, 2003.

TEECE, David J.; PISANO, Gary; SHUEN, Amy. Dynamic Capabilities and Strategic Management. Strategic Management Journal, v. 18, n. 7, p. 509-533, 1997.

WENGER, Etienne. Communities of practice: Learning, meaning, and identity. Cambridge University Press, 1999.

VENKATRAMAN, Natarjan; RAMANUJAM, Vasudevan. Measurement of business economic performance: An examination of method convergence. Journal of Management, v. 13, n. 1, p. 109122, 1987.

VENKATRAMAN, Nenkat; GRANT, John H. Construct measurement in organizational strategy research: A critique and proposal. Academy of Management Review, n. 11, v. 1, p. 71-87, 1986.

WERNERFELT, Birger. A resource-based view of the firm. Strategic Management Journal, v. 5, n. 2, p. 171-180, 1984.

ZARIFIAN, Philippe. A gestão da e pela competência. Rio de Janeiro: Centro Internacional para Educação, Trabalho e Transferência de Tecnologia, 1996.

Artigo recebido em 18/07/2016 e aceito para publicação em 01/03/2017

Perspectivas em Gestão \& Conhecimento, João Pessoa, v. 7, Número Especial, p. 4-17, mar. 2017. 